\author{
EVS29 Symposium \\ Montréal, Québec, Canada, June 19 - 22, 2016
}

\title{
Study on Energy System Configuration of Wireless In-Wheel Motor with Supercapacitor
}

\author{
Takuma Takeuchi $^{1}$, Takehiro Imura ${ }^{2}$, Hiroshi Fujimoto ${ }^{3}$, Yoichi Hori ${ }^{4}$, Daisuke Gunji $^{5}$ \\ ${ }^{1-4}$ The University of Tokyo, 5-1-5,Kashiwanoha, Kashiwa, Chiba, 277-8561, Japan, ${ }^{1}$ takeuchi15@hflab.k.u-tokyo.ac.jp \\ ${ }^{5}$ NSK Ltd., 1-5-50, Kugenumashinmei, Fujisawa, Kanagawa, 251-8501, Japan
}

\begin{abstract}
In-Wheel Motor (IWM) have been proposed to increase an efficiency and controllability of electric vehicle (EV). However, a risk of disconnection of power lines have been considered as a fundamental problem of IWM. Therefore, we proposed Wireless In-Wheel Motor (W-IWM) to solve this problem radically by using Wireless Power Transfer (WPT). In this paper, an advanced system of W-IWM which has multiple power sources, supercapacitor and dynamic charging circuit on its wheel side is proposed for a more effective operation. Additionally, a power-flow control of the advanced system is proposed and is verified by simulations and experiments. Furthermore, efficiency of the proposed system is investigated.
\end{abstract}

Keywords: EV, In-Wheel Motor, Wireless Power Transfer, Wireless In-Wheel Motor, Supercapacitor, Energy system, Power-flow

\section{Introduction}

Electric vehicle (EV) has been gathered a great deal of public attention from the perspective of environmental performance. However, due to a limited battery capacity, EV has been only able for a short distance. To deal with this issue, a number of studies have been done on range extension of EV [1] [2].

Especially vehicle motion control using In-Wheel Motor (IWM) can increase not only a driving efficiency but also a driving safety by its high controllability [3] [4]. In-Wheel Motor is one of the propagation system for EV realizing independent torque control of each wheels. Nevertheless, IWM has not been put into practical use because of the risk of power lines disconnection. Therefore we have proposed Wireless In-Wheel Motor (W-IWM) to solve this problem radically and make IWM more practical by using Wireless Power Transfer (WPT) via magnetic resonance coupling [5].

In the purpose of a more efficient operation of W-IWM, we have proposed an advanced energy system of W-IWM having supercapacitor on its wheel side for a more effective regeneration and a circuit for dynamic charging. By applying Hybrid Energy Storage System [8] [9], we propose a novel powerflow control for W-IWM system with multiple power sources on the wheel side. The proposed powerflow control is verified by simulation and experiment. Furthermore, we measured the efficiency of the proposed system and verified the effectiveness of the proposed system.

\section{Wireless In-Wheel Motor (W-IWM)}

Figure 1 shows the first trial unit of W-IWM which was successfully drove the experimental vehicle shown in figure 2 . The maximum power of the unit is $3.3 \mathrm{~kW} /$ wheel and DC to DC efficiency is about $89 \%$. The gap between a chassis side transmitter coil to a wheel side receiver coil is $100 \mathrm{~mm}$. Figure 
3 shows the previous system of W-IWM which has SS topology for wireless power transfer. This system is configured symmetrically at the chassis side and the wheel side for bidirectional power transfer. Therefore it can regenerate power from the wheel side to the chassis side.

Due to an instability of a motor driving system with WPT using SS topology, a wheel side DC-link voltage control is necessary [6]. The wheel side voltage control of W-IWM is achieved by using a hysteresis control [7]. Hysteresis control accomplishes the voltage control and a power control at the same time.

The maximum power of MITSUBISHI i-MiEV (the base vehicle of the experimental vehicle) is 47 $\mathrm{kW}$. On the other hand, the experimental vehicle is expected to generate $13.2 \mathrm{~kW}$ with W-IWM on its all wheels. Improving the output power and efficiency are required for furthermore practicability.

\section{Proposed system}

\subsection{Second trial unit (W-IWM2)}

Considering a requirement for range extension of EV, more effective system is desired. In this paper, to achieve these goal, an advanced system of W-IWM is proposed. Figure4 shows circuit structure of the proposed system of second trial unit of W-IWM (W-IWM2). This system has Lithium ion Capacitor (LiC) connected to wheel side DC-link through DC/DC converter and dynamic charging circuit connected through AC/DC converter. Therefore wheel power can be regenerated to LiC or get power from road side transmitter.

In proposed system, because of regenerative power go through less converters compared to the previous system, DC to DC regenerative efficiency is expected to improve $89 \%$ to $96 \%$. Additionally, since dynamic charging can be applied on this system, a more effective operation and range extension are expected.

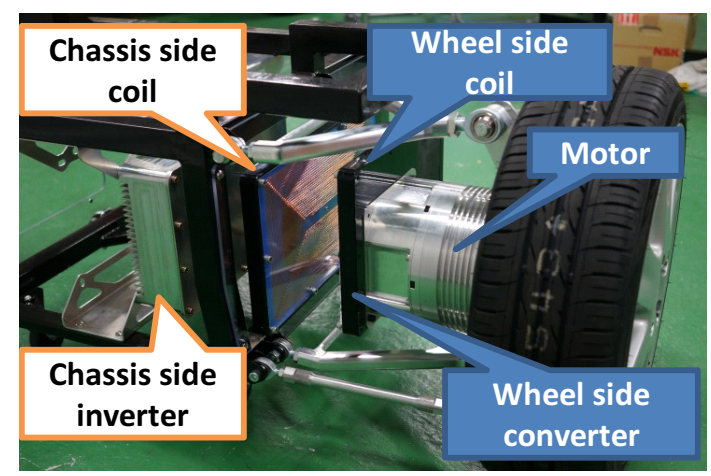

Figure 1: First trial unit of W-IWM

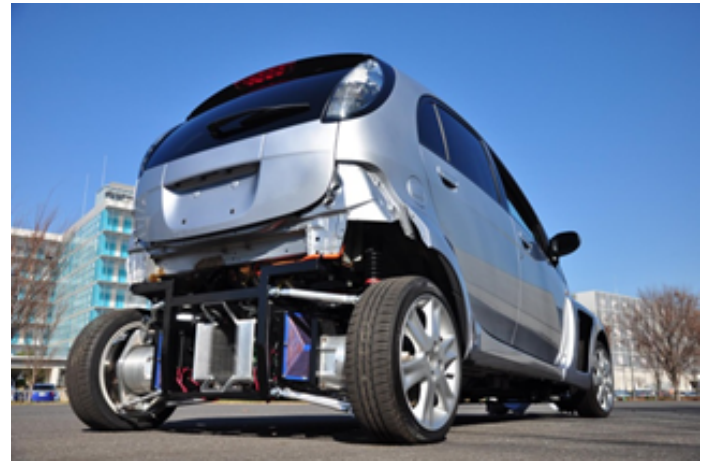

Figure 2: Experimental vehicle

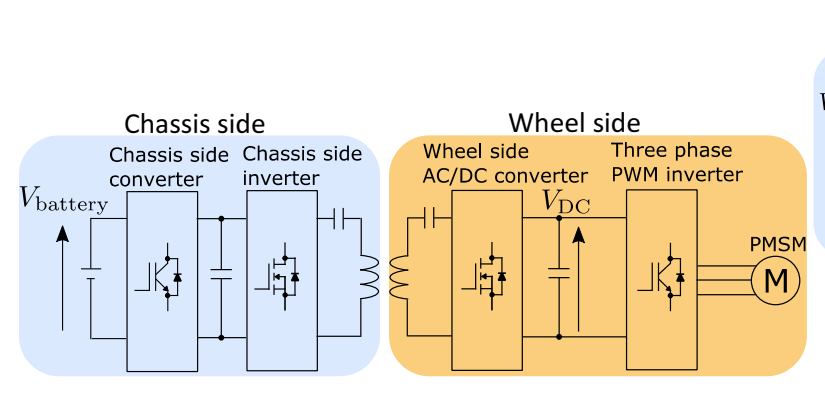

Figure 3: Previous system of W-IWM

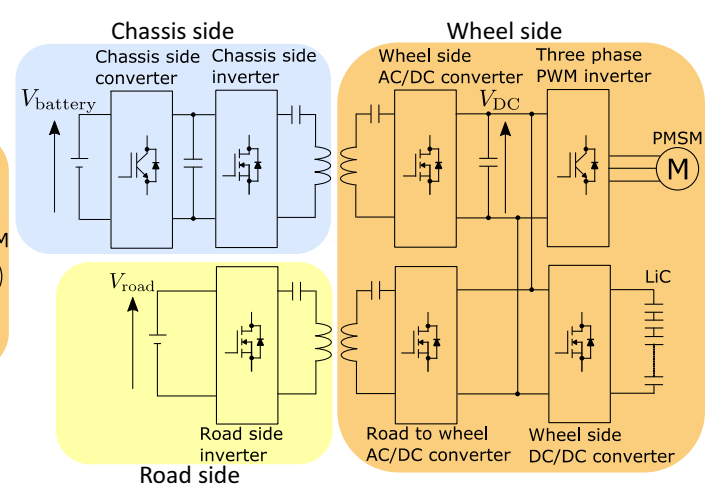

Figure 4: Proposed system of W-IWM2 


\section{Proposed power-flow control}

W-IWM2 has multiple power sources on the wheel side different from W-IWM. Therefore a power-flow control on these power sources is required for a stability of motor drive.

\subsection{Wheel side converters}

\subsubsection{Wheel side DC/DC converter}

W-IWM stabilizes the wheel side DC-link voltage $V_{\mathrm{DC}}$ using hysteresis control on the wheel side AC/DC converter. On the other hand, W-IWM2 controls $V_{\mathrm{DC}}$ using a feedback control on a wheel side DC/DC converter for chassis. Herewith, the wheel side DC/DC converter restrains change of $V_{\mathrm{DC}}$ and $\mathrm{LiC}$ compensates the power balance by changing a power of $\mathrm{LiC} P_{\mathrm{LiC}}$ automatically. Accordingly, a wheel side power-flow control can be achieved just using the feedback control of $V_{\mathrm{DC}}$ on the wheel side $\mathrm{DC} / \mathrm{DC}$ converter.

\subsection{2 wheel side AC/DC converter}

W-IWM2 controls a transmitting power from the chassis side to the wheel side $P_{\text {WPT }}$ using the wheel side AC/DC converter. Hence, $P_{\mathrm{LiC}}$ can be controlled indirectly.

By means of these two controls, a relational expression on the power-flow of the wheel side is completed with the voltage feedback control on the wheel side DC/DC converter.

$$
P_{\mathrm{L}}=P_{\mathrm{WPT}}+P_{\mathrm{LiC}}
$$

where $P_{\mathrm{L}}$ is load power of PMSM and 3 phase PWM inverter.

In proposed system, $V_{\mathrm{DC}}$ is controlled by the wheel side $\mathrm{DC} / \mathrm{DC}$ converter and 2 mode control [6] is utilized for controlling $P_{\mathrm{WPT}}$ on the wheel side AC/DC converter. Thus, $P_{\mathrm{WPT}}$ can be controlled by the wheel side only. Moreover, $\mathrm{LiC}$ powers the motor or be charged automatically by changing the powerflow on the wheel side. Therefore, this system can operate with multiple power sources. Furthermore, controlling $P_{\mathrm{WPT}}$ indicates that power of SC $P_{\mathrm{LiC}}$ can be controlled indirectly. Applying proposed control method for the system, the power-flow control is practicable. Figure 5 shows the block diagram of the power-flow control.

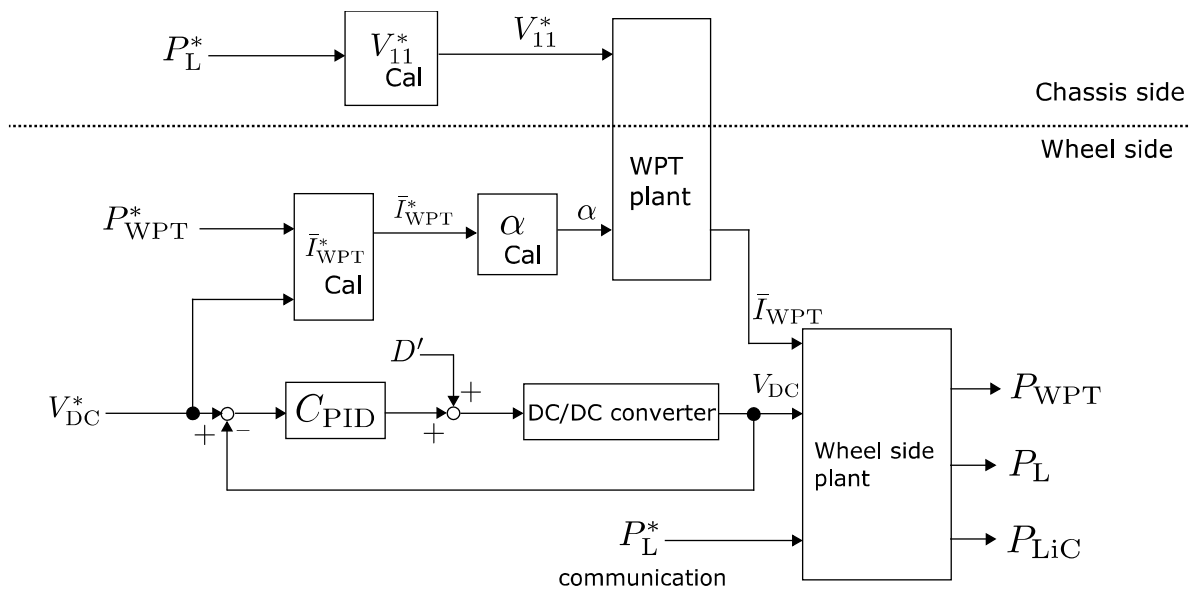

Figure 5: Block diagram of proposed power-flow control

\subsection{Controllers}

\subsubsection{Voltage feedback control on wheel side DC/DC converter}

Figure 6 shows a circuit mode of the wheel side DC/DC converter, where $V_{\mathrm{LiC}}$ is voltage of LiC, $r$ is ESR of $\mathrm{LiC}$ and reactor, $L$ is reactance of DC/DC converter, $I_{\mathrm{LiC}}$ is reactor current, $I_{\text {load }}$ is load current and $C$ is capacitance of the wheel side DC-link smoothing capacitor. In this model, PMSM and 3 phase PWM inverter are modeled by current source. 
To analysis this circuit, the state-space averaging method is applied. In this paper, because of switching of this half bridge is reciprocal, this model works in continuous current mode. Since the system includes nonlinearity, linearizion is conducted on its equilibrium point as

$$
\begin{aligned}
\frac{d}{d t} x(t) & =\left[\begin{array}{cc}
-\frac{r}{L} & -\frac{(1-d(t))}{L} \\
\frac{1}{C} & 0
\end{array}\right] x(t)+\left[\begin{array}{cc}
0 & \frac{1}{L} \\
-\frac{1}{C} & 0
\end{array}\right]\left[\begin{array}{l}
i_{\text {load }}(t) \\
V_{\mathrm{LiC}}(t)
\end{array}\right] \\
v_{\mathrm{DC}}(t) & =\left[\begin{array}{ll}
0 & 1
\end{array}\right] x(t) \\
x(t) & =\left[\begin{array}{ll}
i_{\mathrm{LiC}}(t) & v_{\mathrm{DC}}(t)
\end{array}\right]
\end{aligned}
$$

where $d(t)$ indicates the time of lower arm switch.

By assuming the fluctuation of equilibrium point is slow compare with carrier period, each equilibrium points of $i_{\text {load }}(t), i_{\mathrm{LiC}}(t), \quad v_{\mathrm{DC}}(t), d(t)$ can be described by $I_{\text {load }}, I_{\mathrm{LiC}}, V_{\mathrm{DC}}, D$ as

$$
\begin{aligned}
D^{\prime} & =\frac{V_{\mathrm{LiC}}+\sqrt{V_{\mathrm{LiC}}^{2}-4 r V_{\mathrm{DC}} I_{\text {load }}}}{2 V_{\mathrm{DC}}} \\
I_{\mathrm{LiC}} & =\frac{I_{\text {load }}}{D^{\prime}}
\end{aligned}
$$

where $D^{\prime}=1-D\left(0 \leq D^{\prime} \leq 1\right)$. Then, minute variations $\Delta i_{\text {load }}, \Delta i_{\mathrm{LiC}}, \Delta v_{\mathrm{DC}}, \Delta d i_{\text {load }}(t)$ of $i_{\mathrm{LiC}}(t)$, $v_{\mathrm{DC}}(t), d(t)$ are derived as

$$
\begin{aligned}
\frac{d}{d t} \Delta x(t) & =\left[\begin{array}{cc}
-\frac{r}{L} & -\frac{D^{\prime}}{L} \\
\frac{D^{\prime}}{C} & 0
\end{array}\right] x(t)+\left[\begin{array}{cc}
\frac{-V_{\mathrm{DC}}}{L} & 0 \\
\frac{I_{\mathrm{LiC}}}{C} & \frac{-1}{C}
\end{array}\right] u(t) \\
\Delta v_{\mathrm{DC}}(t) & =\left[\begin{array}{ll}
0 & 1
\end{array}\right] \Delta x(t) \\
\Delta x(t) & =\left[\begin{array}{ll}
\Delta i_{\mathrm{LiC}}(t) & \Delta v_{\mathrm{DC}}(t)
\end{array}\right], u(t)=\left[\begin{array}{ll}
d^{\prime}(t) & i_{\text {load }}(t)
\end{array}\right] .
\end{aligned}
$$

From formula (6), (7), the transfer function $\Delta P_{\mathrm{v}}$ from $\Delta d^{\prime}(s)$ to $\Delta v_{\mathrm{DC}}(s)$ is,

$$
\begin{aligned}
\Delta P_{\mathrm{v}} & =\frac{b_{\mathrm{p} 1} s+b_{\mathrm{p} 0}}{s^{2}+a_{\mathrm{p} 1} s+a_{\mathrm{p} 0}} \\
a_{\mathrm{p} 1} & =\frac{r}{L}, a_{\mathrm{p} 0}=-\frac{D^{\prime}}{L C} \\
b_{\mathrm{p} 1} & =\frac{I_{\mathrm{LiC}}}{C}, b_{\mathrm{p} 0}=\frac{r I_{\mathrm{LiC}}-D^{\prime} V_{\mathrm{DC}}}{L C} .
\end{aligned}
$$

On this transfer function, we design the quadrupole of PID controller on $-1000 \mathrm{rad} / \mathrm{s}$ and discretized it using tustin transfer with sampling period $T_{\mathrm{s}}$.

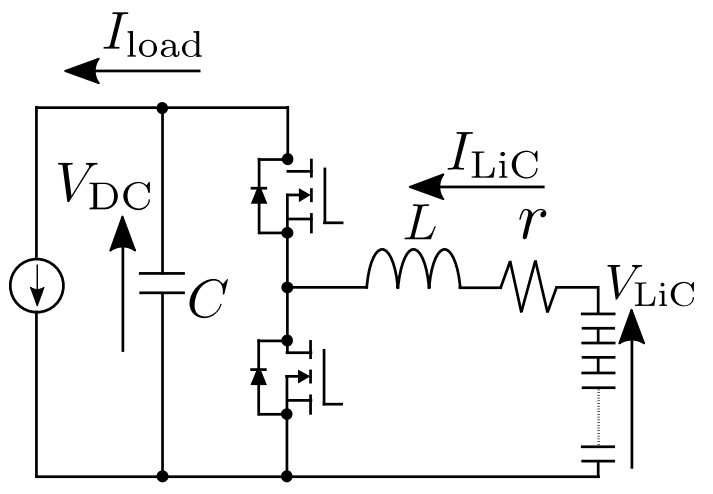

Figure 6: Circuit model of wheel side DC/DC converter 


\subsubsection{Power control on wheel side AC/DC converter}

The wheel side AC/DC converter controls the transmitting power from the chassis side to the wheel side by 2 mode control [6]. Figure 7 shows operation modes of the wheel side AC/DC converter with 2 mode control.

Short mode The under side switches of the wheel side AC/DC converter is turn on. Then the wheel side receiver coil shorts from the wheel side circuit as showed figure 7(a) and does not supply the transmitting power from the chassis side to the wheel side.

Rectification mode The wheel side AC/DC converter operates as a rectifier. The wheel side receives the transmitting power from chassis to wheel.

By converting two modes mentioned above periodically, we are able to control $\bar{I}_{\mathrm{WPT}}$. Assuming that the wheel side coil current is a sinusoidal current with the resonant frequency, an input voltage of the wheel side AC/DC converter can be approached to its fundamental harmonic. Moreover, an approximate value of an effective current of the wheel side coil $I_{21}$ is determined as below.

$$
I_{21} \simeq \frac{\omega_{0} L_{\mathrm{m}} V_{11}-\frac{2 \sqrt{2}}{\pi} R_{1} V_{\mathrm{DC}}}{R_{1} R_{2}+\left(\omega_{0} L_{\mathrm{m}}\right)^{2}}
$$

where, $\omega_{0}$ is resonance angular frequency, $L_{\mathrm{m}}$ is mutual inductance between the chassis side and the wheel side coils and $R_{1}, R_{2}$ are the chassis side, the wheel side coils resistance. An output current on each mode $I_{\mathrm{dc}}$ is expressed as below.

$$
I_{\mathrm{WPT}}= \begin{cases}0 & \text { (Short mode) } \\ \frac{2 \sqrt{2}}{\pi} I_{21} & \text { (Rectification mode) }\end{cases}
$$

Therefore,

$$
\bar{I}_{\mathrm{WPT}}=\alpha I_{\mathrm{WPT}}
$$

where, $\alpha$ means time ratio of rectification mode. Consequently, we can control an average output current of the wheel side AC/DC converter $\bar{I}_{\mathrm{WPT}}$ and the transmitting power from the chassis side via WPT $P_{\text {WPT }}$ by changing $\alpha$.

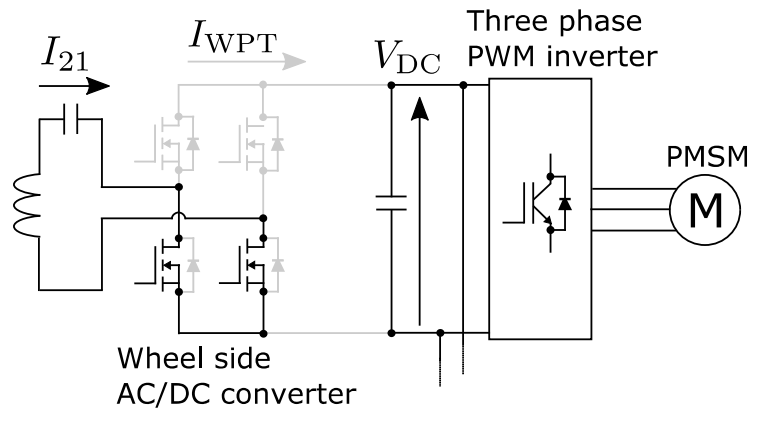

(a) Short mode

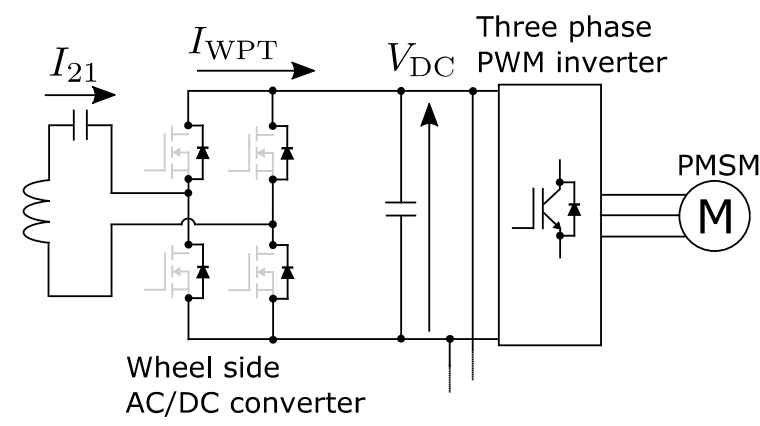

(b) Rectification mode

Figure 7: Operation mode of 2 mode control.

\section{Simulation and Experiment}

\subsection{Experimental setup}

Figure 8(a) shows a circuit diagram of a small power experimental setup. The circuit for dynamic charging is excluded in this paper. To simplify the setup, a regenerative DC power supply (pQUBE MWBFP3-1250-J02 : Myway) replaces the PMSM and 3 phase PWM inverter. A DC power supply (PU300-5 : TEXIO) replaces DC-link on chassis side. Figure 8(b) shows the small power experimental setup. 
The experimental results are sampled at $50 \mathrm{kHz}$. We filtered a result of power by moving average with a window size 100 to reduce an effect of $V_{D C}$ ripple which causes by 2 mode control of the wheel side AC/DC converter. We applied $1 \mathrm{kHz}$ primary low pass filter on the load current $I_{\mathrm{L}}$ and current on supercapacitor $I_{\mathrm{LiC}}$. Furthermore, we applied $500 \mathrm{~Hz}$ primary low pass filter on the output averaging current of the wheel side AC/DC converter $\bar{I}_{\mathrm{WPT}}$.

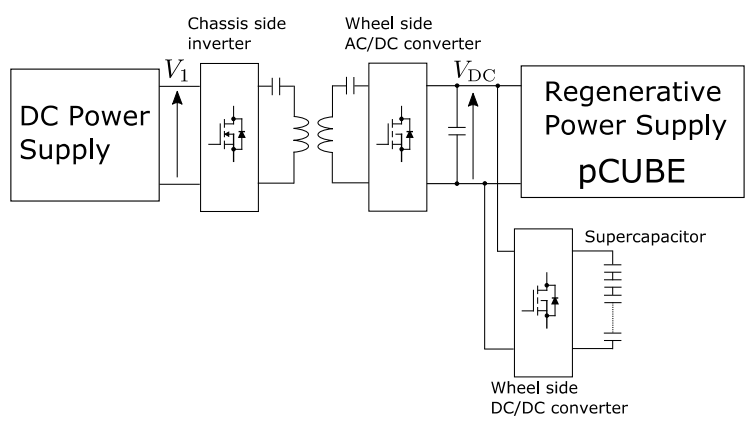

(a) Experimental circuit

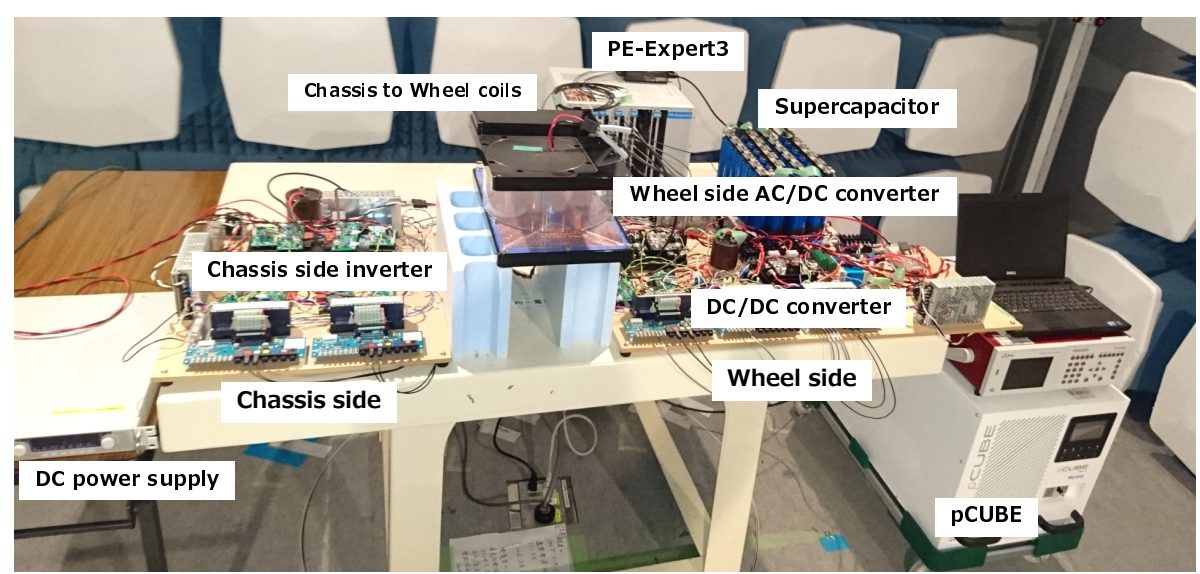

(b) Experimental setup

Figure 8: Experimental setup.

\subsection{Simulation}

We performed simulations on the proposed power-flow control using MATLAB Simulink Simpower Systems. Simulation conditions are determined, considering the value of W-IWM2 which values are given in table 1 . Now, the maximum output $12 \mathrm{~kW}$ is determined by assuming that the experimental vehicle with W-IWM2 on its all wheels achieves the equivalent output of MITSUBISHI i-MiEV $47 \mathrm{~kW}$. Furthermore, the operation voltage of $\mathrm{LiC}$ is assumed 38.4-57.6 V and $48 \mathrm{~V}$ ( $\mathrm{SOC}=0.5$ ) was used as nominal voltage on the simulation. To simplify the simulation, we replaced LiC by voltage source. The wheel side DC-link voltage $V_{\mathrm{DC}}$ and a fundamental value of effective voltage of the chassis side inverter output $V_{11}$ are determined by formula (14),(15) to make transmitting efficiency of WPT between the chassis side and the wheel side maximum. Moreover, we took $8 \mathrm{~kW}$ for $P_{\mathrm{WPT}}$.

$$
\begin{aligned}
R_{\eta \mathrm{opt}} & =\sqrt{\frac{R_{2}}{R_{1}}\left(\omega_{0} L_{\mathrm{m}}\right)^{2}+R_{2}^{2}} \\
V_{\mathrm{DC}} & =\frac{\pi}{2 \sqrt{2}} \sqrt{R_{\eta \mathrm{opt}} P_{\mathrm{WPT}}} \\
V_{11} & =\frac{\left\{R_{1} R_{2}+R_{1} R_{\eta \mathrm{opt}}+\left(\omega_{0} L_{\mathrm{m}}\right)^{2}\right\} \sqrt{\frac{P_{\mathrm{WPT}}}{R_{\eta \mathrm{opt}}}}+\frac{2 \sqrt{2}}{\pi} R_{1} V_{\mathrm{DC}}}{\omega_{0} L_{\mathrm{m}}}
\end{aligned}
$$

Where $R_{\mathrm{ac}}$ is equivalent $\mathrm{AC}$ resistance of the wheel side and $R_{\eta \mathrm{opt}}$ is equivalent $\mathrm{AC}$ resistance of the wheel side at the maximum efficiency of WPT $(\alpha=1)$. Simulation results are sampled at $20 \mathrm{kHz}$. Moving average with a window size 40 is applied to reduce an effect of $V_{D C}$ ripple which causes by 2 mode control of the wheel side AC/DC converter. 
Table 1: Simulation and experimental parameters.

\begin{tabular}{|c|c|c|}
\hline & Sim. & Exp. \\
\hline Resonance frequency & $85 \mathrm{kHz}$ & $85 \mathrm{kHz}$ \\
\hline Switching frequency of DC/DC converter & $40 \mathrm{kHz}$ & $40 \mathrm{kHz}$ \\
\hline Switching frequency of 2mode control & $500 \mathrm{~Hz}$ & $500 \mathrm{~Hz}$ \\
\hline DC-link voltage reference $V_{\mathrm{DC}}^{*}$ & $337.9 \mathrm{~V}$ & $200.0 \mathrm{~V}$ \\
\hline Maximum output & $12.0 \mathrm{~kW}$ & $1.0 \mathrm{~kW}$ \\
\hline LiC capacitance & $93.8 \mathrm{~F}$ & $95.8 \mathrm{~F}$ \\
\hline LiC nominal voltage & $48 \mathrm{~V}$ & $50 \mathrm{~V}$ \\
\hline Chassis side coil resistance $R_{1}$ & $400.0 \mathrm{~m} \Omega$ & $558.09 \mathrm{~m} \Omega$ \\
\hline Chassis side coil inductance $L_{1}$ & $270 \mu \mathrm{H}$ & $269.63 \mu \mathrm{H}$ \\
\hline Wheel side coil resistance $R_{2}$ & $300.0 \mathrm{~m} \Omega$ & $361.81 \mathrm{~m} \Omega$ \\
\hline Wheel side coil inductance $L_{2}$ & $250 \mu \mathrm{H}$ & $224.51 \mu \mathrm{H}$ \\
\hline Coil gap & $100 \mathrm{~mm}$ & $100 \mathrm{~mm}$ \\
\hline Coil mutual inductance $L_{\mathrm{m}}$ & $25.0 \mu \mathrm{H}$ & $25.78 \mu \mathrm{H}$ \\
\hline Smoothing capacitance $C$ & $2200 \mu \mathrm{F}$ & $2145 \mu \mathrm{F}$ \\
\hline Inductance of DC/DC converter $L$ & $60.8 \mu \mathrm{H}$ & $60.8 \mu \mathrm{H}$ \\
\hline ESR of inductance and LiC $r$ & $31.4 \mathrm{~m} \Omega$ & $41.0 \mathrm{~m} \Omega$ \\
\hline
\end{tabular}

\subsubsection{Power-flow transition with load change}

Figure 9 shows a power-flow transition with the stepwise load change. $\alpha$ decided 0.75 to make $P_{\mathrm{WPT}}$ $6 \mathrm{~kW}$. Load changed stepwise from $12 \mathrm{~kW}$ powering to $-6 \mathrm{~kW}$ regenerate. Figure 10 shows simulation results. Figure 10 (a) shows power of each power sources and $P_{\mathrm{LiC}}$ is controlled automatically by only applying the voltage feedback control on the wheel side DC/DC converter. Figure 10(b) shows that the voltage feedback control of the wheel side DC/DC converter stabilizes $V_{\mathrm{DC}}$ before and after the load change. Note that, ripple of $V_{\mathrm{DC}}$ is caused by 2 mode control. Accordingly, the power-flow control effects solely by applying the voltage feedback control on the wheel side DC/DC converter.

\subsubsection{Power-flow transition with $P_{\mathrm{WPT}}$ change}

Figure 11 shows a power-flow with $P_{\mathrm{WPT}}$ change. $\alpha$ is changed stepwise to make $P_{\mathrm{WPT}}$ from 4.0 $\mathrm{kW}$ to $7.0 \mathrm{~kW}$. Figure 12 shows the simulation result. Figure 12(a) shows power of each power sources and indicates that $P_{\mathrm{LiC}}$ is controlled indirectly by changing $P_{\mathrm{WPT}}$ with 2 mode control on wheel side AC/DC converter. Figure 12(b) shows that the voltage feedback control of wheel side DC/DC converter stabilizes $V_{\mathrm{DC}}$ before and after $P_{\mathrm{WPT}}$ change. Note that, ripple of $V_{\mathrm{DC}}$ is caused by 2 mode control.

Accordingly, the power-flow control is achieved only by the voltage feedback control on the wheel side DC/DC converter and $P_{\mathrm{LiC}}$ is determined automatically. Moreover, $P_{\mathrm{LiC}}$ can be controlled indirectly with 2 mode control using the wheel side AC/DC converter.

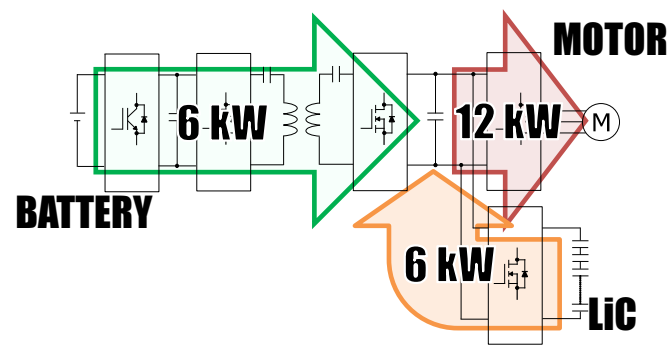

(a) Load powering

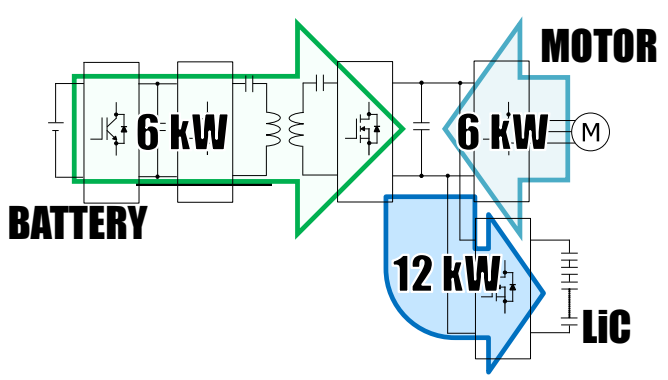

(b) Load regeneration

Figure 9: Power-flow transition with load change. 


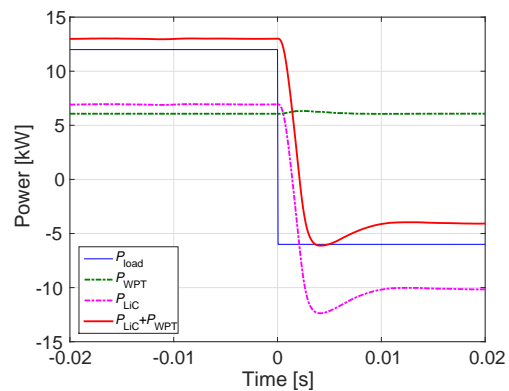

(a) Power

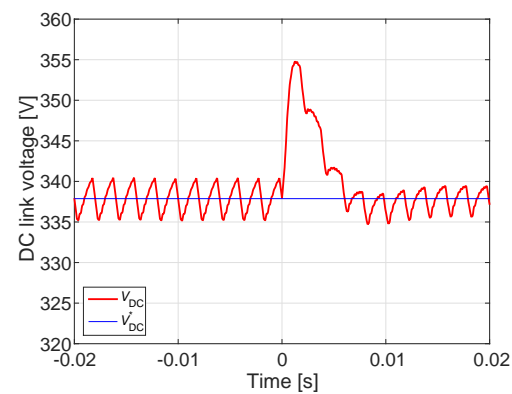

(b) DC-link voltage $V_{\mathrm{DC}}$

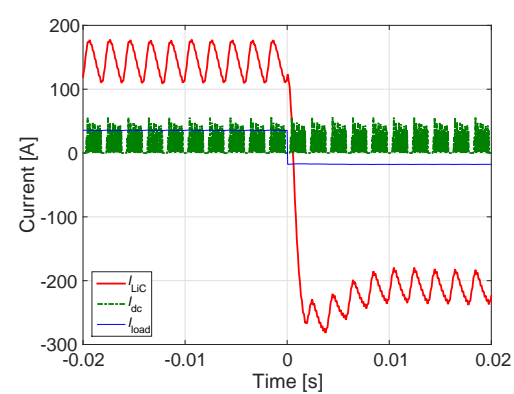

(c) Current

Figure 10: Power-flow transition with load change simulation result.

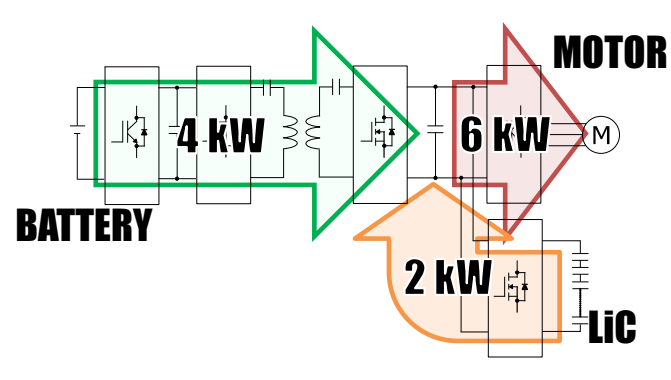

(a) $P_{\mathrm{WPT}}=4.0 \mathrm{~kW}$

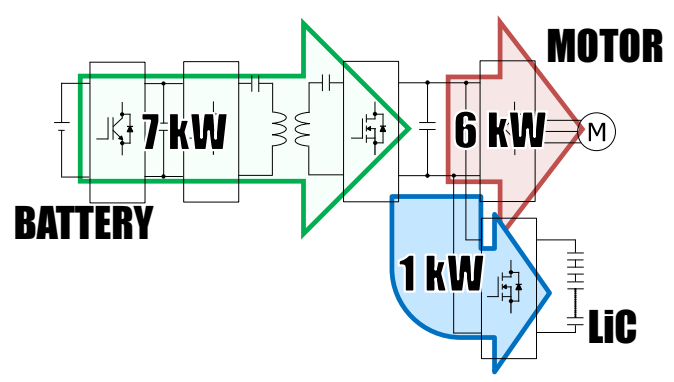

(b) $P_{\mathrm{WPT}}=7.0 \mathrm{~kW}$

Figure 11: Power-flow transition with $P_{\mathrm{WPT}}$ change.

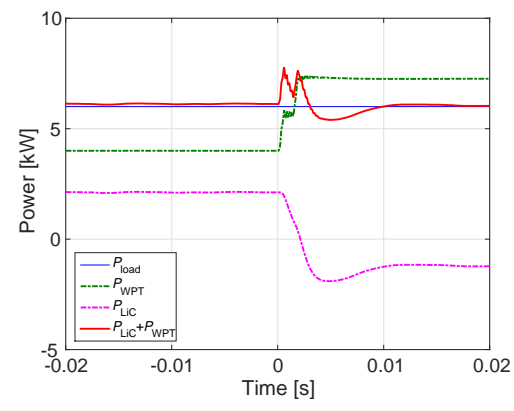

(a) Power

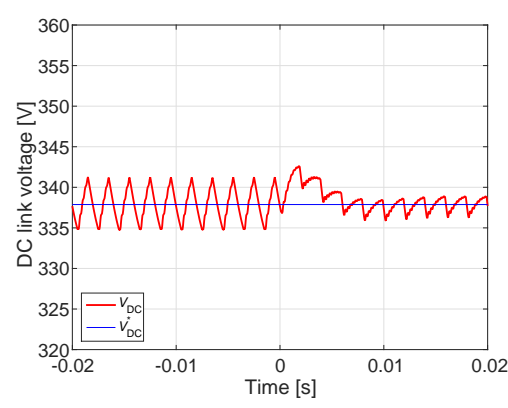

(b) DC-link voltage $V_{\mathrm{DC}}$

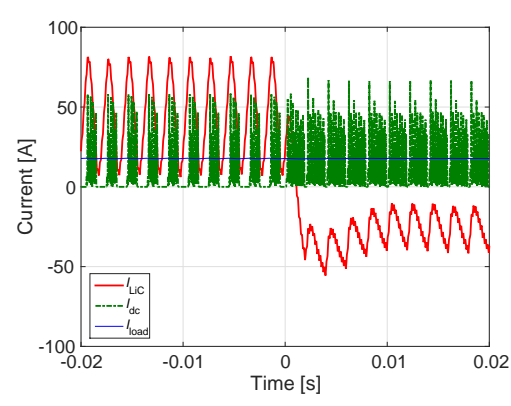

(c) Current

Figure 12: Power-flow transition with $P_{\mathrm{WPT}}$ change simulation result. 
Table 2: Experimental condition and result on efficiency measurement of the wheel side DC/DC converter.

\begin{tabular}{|c|c|}
\hline Parameter & Value \\
\hline Switching frequency of DC/DC converter & $40 \mathrm{kHz}$ \\
\hline Switching dead time & $600 \mathrm{nsec}$ \\
\hline DC-link voltage reference $V_{\mathrm{DC}}^{*}$ & $200 \mathrm{~V}$ \\
\hline Load output & $1000 \mathrm{~W}$ \\
\hline SC capacitance & $95.83 \mathrm{~F}$ \\
\hline SC nominal voltage & $50 \mathrm{~V}$ \\
\hline Smoothing capacitance $C$ & $2145 \mu \mathrm{F}$ \\
\hline Inductance of DC/DC converter $L$ & $60.8 \mu \mathrm{H}$ \\
\hline ESR of inductance and SC $r$ & $41.0 \mathrm{~m} \Omega$ \\
\hline DC to DC efficiency & $95.2 \%$ \\
\hline
\end{tabular}

\subsection{Experiment}

We conducted congenial experiments as simulations using the small power experimental setup. Additionally, we investigate the efficiency of the wheel side DC/DC converter.

\subsubsection{Power-flow transition with load change}

Figure 13 shows an experimental result of a power-flow transition with load change. During transmitting a constant power via WPT from chassis to wheel, load changed $1.2 \mathrm{~W}$ powering to $-0.6 \mathrm{~kW}$ regeneration. Because of the wheel side DC/DC converter controls $V_{\mathrm{DC}}, P_{\mathrm{LiC}}$ compensates the power-flow change. Figure 13(a) shows power of each wheel side power sources. By applying the voltage feedback control on the wheel side DC/DC converter, the wheel side power-flow control is achieved automatically. Figure 13 (b) shows $V_{\mathrm{DC}}$. Before and after the load change, $V_{\mathrm{DC}}$ is stabilized by the voltage feedback control of the wheel side DC/DC converter. Note that, ripple of $V_{\mathrm{DC}}$ is caused by 2 mode control.

\subsubsection{Power-flow transition with $P_{\mathrm{WPT}}$ change}

Figure 14 the shows an experimental result of power-flow transition with $P_{\mathrm{WPT}}$ change. While the load is powering $0.6 \mathrm{~kW}, P_{\mathrm{WPT}}$ is changed from $0.3 \mathrm{~kW}$ to $0.6 \mathrm{~kW}$ stepwise using the wheel side AC/DC converter with 2 mode control. Figure 14(b) shows that change of $V_{\mathrm{DC}}$ accompanied by $P_{\mathrm{WPT}}$ change. Before and after the $P_{\mathrm{WPT}}$ change, $V_{\mathrm{DC}}$ is stabilized by the voltage feedback control of the wheel side DC/DC converter. Note that, ripple of $V_{\mathrm{DC}}$ is caused by 2 mode control. Figure14(a) shows that power of supercapacitor $P_{\mathrm{LiC}}$ is controlled by $P_{\mathrm{WPT}}$ indirectly.

Therefore, proposed power-flow control, synthesis of $V_{\mathrm{DC}}$ control of DC/DC converter and 2 mode control on wheel side AC/DC converter, is verified by experiments.

\subsubsection{Efficiency measurement on wheel side DC/DC converter}

We measured DC to DC efficiency of the wheel side DC/DC converter from supercapacitor to regenerative power supply powering at $1 \mathrm{~kW}$ using power analyzer (PPA5530 : IWATSU). To reduce the size of the wheel side DC/DC converter, we use a small inductor and the inductance of this small inductor is $60.8 \mu \mathrm{H}$. Therefore we operates the wheel side DC/DC converter at a switching frequency $40 \mathrm{kHz}$ to reduce a current ripple. Table2 shows experimental condition and result of the experiment. The efficiency of the wheel side DC/DC converter powering $1.0 \mathrm{~kW}$ was $95.2 \%$. Consequently, the regenerative efficiency of the proposed system is expected to improve $89 \%$ to $95.2 \%$.

\section{Conclusion}

In this research, we proposed advanced energy system configuration of W-IWM. This system has supercapasitor and circuit for dynamic charging on the wheel side. The power-flow of the system is controlled by the voltage feedback control on wheel side DC/DC converter only. Moreover, output/input power of supercapacitor is controlled indirectly by 2 mode control on the wheel side AC/DC converter. Therefore, the proposed power-flow control, synthesis of the voltage feedback control on the wheel side 


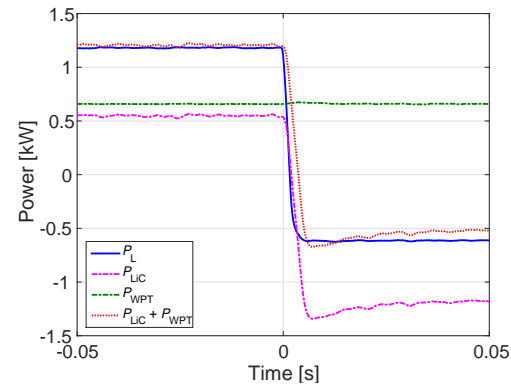

(a) Power

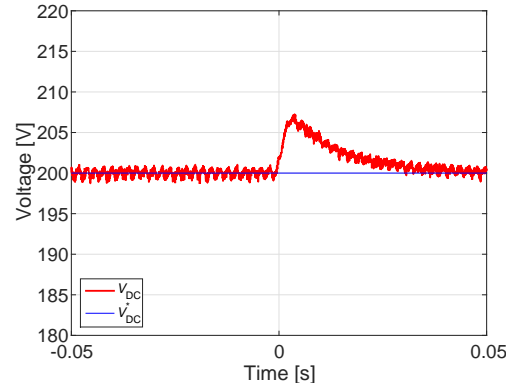

(b) DC-link voltage $V_{\mathrm{DC}}$

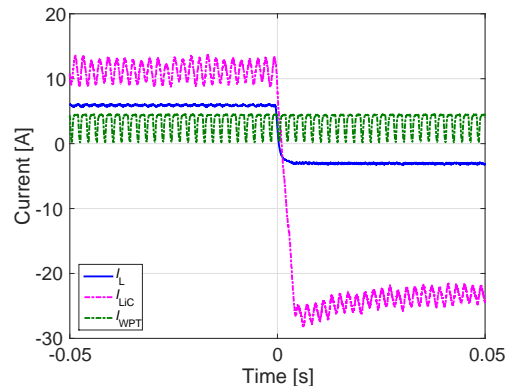

(c) Current

Figure 13: Power-flow transition with load change experimental result.

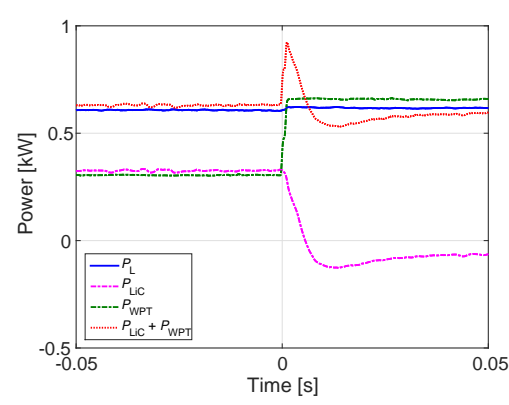

(a) Power

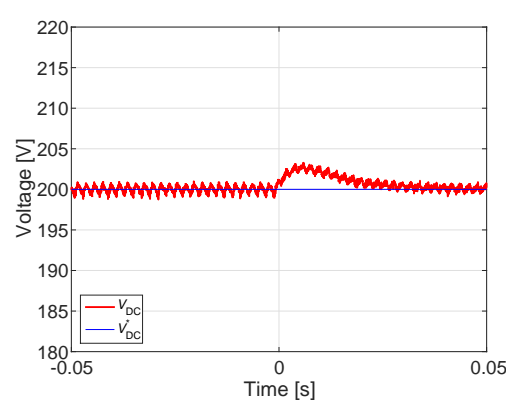

(b) DC-link voltage $V_{\mathrm{DC}}$

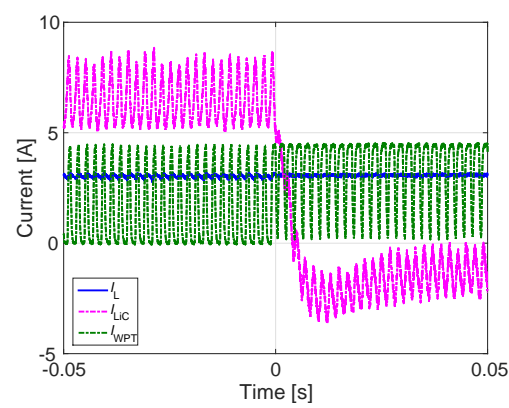

(c) Current

Figure 14: Power-flow transition with $P_{\mathrm{WPT}}$ change experimental result.

DC/DC converter and 2 mode control on the wheel side AC/DC converter are verified by simulation and experiment. Moreover we investigated the efficiency of the wheel side DC/DC converter and the efficiency was $95.2 \%$. Comparing that the DC to DC efficiency of regeneration using WPT is about $89 \%$ to the efficiency using the wheel side DC/DC converter $95.2 \%$, the effectiveness of the advanced system was verified.

\section{References}

[1] Atsuo Kawamura, Giuseppe Guidi, Yuki Watanabe, Yukinori Tsuruta, Naoki Motoi and Tae-Woong Kim:“Driving Performance Experimental Analysis of Series Chopper Based EV Power Train”, Journal of Power Electronics, Vol.12, No.6, pp.992-1002, (2013).

[2] Stefan Koehler, Alexander Viehl, Oliver Bringmann and Wplfgang Rosentiel:“Improved Energy Efficiency and Vehicle Dynamics for Battery Electric Vehicle through Torque Vectoring Control”, 2015 IEEE Intelligent Vehicle Symposium, pp749-754, (2015).

[3] Satoshi Murata: “innovation by in-wheel-motor drive unit, Vehicle System Dynamics," International Journal of Vehicle Mechanics and Mobility, 50:6, pp.807-830, (2012).

[4] Hiroshi Fujimoto and Shingo Harada: "Model-based Range Extension Control System for Electric Vehicles with Front and Ewar Driving-Braking Force Distributions", IEEE Transaction on Industrial Electronics, pp.3245-3254, (2015).

[5] S. Li and C.C. Mi: "Wireless Power Transfer for Electric Vehicle Applications," IEEE Journal of Emerging and Selected Topics in Power Electronics, Vol.3 No.1, pp.4-17, (2015).

[6] Daisuke Gunji, Takehiro Imura and Hiroshi Fujimoto:"Stability Analysis of Constant power Load and Load Voltage Control Method for Wireless In-Wheel Motor", The 9th International Conference on Power Electronics - ECCE Asis, (2015). 
[7] Gaku Yamamoto, Takehiro Imura and Hiroshi Fujimoto:"Maximizing Power transfer Efficiency of Wirelwss In-Wheel Motor by Primary and Load-Side Voltage Control”, the 1st IEEJ International Workshop on Sensing, Actuation, and Motion Control, TT4-2-1, (2015).

[8] Jian Cao and Ali Emadi: “A New Battery / UltraCapacitor Hybrid Energy Storage System for Electric, Hybrid and Plug-In Hybrid Electric Vehicles," IEEE Transaction on Power Electronics, Vol.27 No.1, pp.122-132, (2012).

[9] Matthew McDonough: "Integration of Inductively Coupled Power Transfer and Hybrid Energy Storage System: A Multiport Power Electronics Interface for Battery-Powered Electric Vehicles," IEEE Transaction on Power Electronics, Vol.30 No.11, pp.6423-6433, (2015).

\section{Authors}

(a)Mr. Takuma Takeuchi received his B.E. degree in electrical engineering from Tokyo University of Science, Tokyo, Japan in 2015. He is currently working toward a M.S. degree at the Graduate School of Frontier Science with the University of Tokyo. His research interests are mainly on wireless power transfer via magnetic resonant couplings.

(b)Dr. Takehiro Imura received his B.S. degree in electrical and electronics engineering from Sophia University, Tokyo, Japan. He received his M.S. degree and Ph.D. in Electronic Engineering from The University of Tokyo in March 2007 and March 2010 respectively. He is currently a Specially Appointed Associate in the Graduate School of Engineering in the same university.

(c)Dr. Hiroshi Fujimoto received his Ph.D. in electrical engineering from The University if Tokyo in 2001. In 2001, he joined the Department of Electrical and Computer Engineering, Nagaoka University as a research associate. From 2002 to 2003, he was a visiting scholar in the School of Mechanical Engineering, Purdue University. In 2004, he joined the Department of Electrical and Computer Engineering, Yokohama National University as a lecturer and he became an associate professor in 2005. He is currently an associate professor of the University of Tokyo since 2010.

(d)Dr. Yoichi Hori received his Ph.D. in electrical engineering from The University of Tokyo, Japan, 1983, where he became a Professor in 2000. In 2008, he moved to the Department of Advanced Energy, Graduate School of Frontier Sciences. Prof. Hori was the recipient of the Best Paper Award from the IEEE Transactions on Industrial Electronics in 1993, 2001 and 2013 and of the 2000 Best Paper Award from the Institute of Electrical Engineers of Japan (IEEJ). He is the Chairman of the Motor Technology Symposium of the Japan Management Association.

(e)Dr. Daisuke Gunji recieved hid Ph.D. in Frontier Science from The University of Tokyo in September 2015. He is currently working at NSK Ltd. in Kanagawa, Japan. His current research and development interest are mainly on underlying technology of Electrical Vehicles.

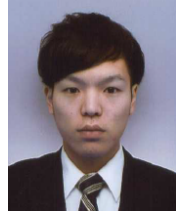

(a)

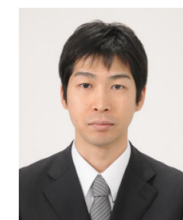

(b)

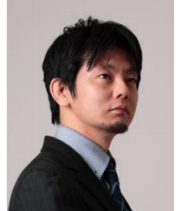

(c)

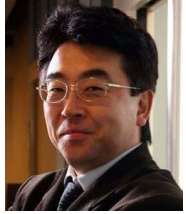

(d)

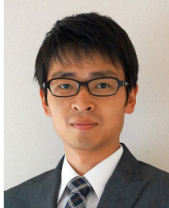

(e) 